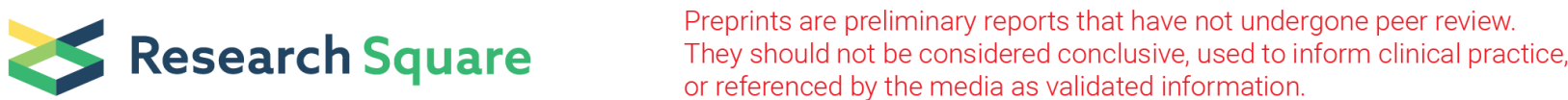

\section{Effect of the duration of intraretinal or subretinal fluid persistence on the response to treatment in undertreated age-related macular degeneration}

Izumi Yoshida ( $\square$ izumi.yoshida@med.toho-u.ac.jp )

Toho Daigaku Iryo Center Sakura Byoin https://orcid.org/0000-0001-8921-052X

Masashi Sakamoto

Sakura medical center of Toho University

Asao Sakai

Sakura medicat center of Toho University

Takatoshi Maeno

Sakura Medical Center of Toho University

\section{Research article}

Keywords: Age-related macular degeneration, anti-VEGF injection, intraretinal fluid, subretinal fluid, visual acuity

Posted Date: October 15th, 2019

DOI: https://doi.org/10.21203/rs.2.16053/v1

License: (c) (i) This work is licensed under a Creative Commons Attribution 4.0 International License. Read Full License

Version of Record: A version of this preprint was published at Journal of Ophthalmology on July 26th, 2020. See the published version at https://doi.org/10.1155/2020/5308597. 


\section{Abstract}

Backgrounds: To investigate the association between intraretinal fluid (IRF) or subretinal fluid (SRF) persistence and response to anti-vascular endothelial growth factor injection in age-related macular degeneration (ARMD).

Methods: Eighty-nine eyes of ARMD patients with VA $\leq 20 / 100$ or persistent subretinal hyper-reflective material were retrospectively assessed. Each injection's efficacy was classified, and fluid accumulation prior to each injection was evaluated. Effect changes within the longest persistent IRF period ( $\geq 10$ months) and their association with previous treatment and accumulated IRF and SRF were determined.

Results: Injection span was shorter and the polypoidal choroidal vasculopathy and occult choroidal neovasculopathy (CNV) proportions were higher among patients with diminished than among those with maintained effects. Throughout observation, acquired refractoriness appeared rarely associated with increased IRF or SRF. VA differed significantly with IRF duration, but not accumulated fluid.

Conclusions: Diminishing effect of injections during long- standing IRF was associated with highly active CNV rather than with undertreatment. The mechanism underlying acquired refractoriness remains unknown; the effect change demonstrated various patterns, including diminished and improved responses. Persistent IRF duration was associated with VA decline. To shorten the duration of persistent IRF, it may be necessary to ensure strict control in refractory patients with high CNV activity.

\section{Background}

The treat-and-extend method for age-related macular degeneration (ARMD) is highly versatile and widely used $[1,2]$. However, there are few reports about treatment effects in patients pre-treated with pro re nata or less over a long period [3,4], who already had poor visual acuity (VA). The Seven-Up Study reported that, after about 7.3 years, $37 \%$ of 65 eyes had best-corrected visual acuity (BCVA) of 20/200 or worse as a result of spontaneous treatment by individual physicians after completion of the HORIZON study. This indicated that 10 patients with poor vision (mean: 21.1 letters) were never suggested treatment during a period of 3.5 years [5]. This was due to a lack of concrete evidence about treatment of long-standing ARMD with poor visual acuity.

In our experience, there were additional problems with long-standing ARMD. First, the likelihood of meaningful visual improvement was poor, even if a dry macula was achieved with anti-vascular endothelial growth factor (VEGF) injection treatment in eyes with decreased VA. Second, some eyes, after long-standing oedema and with destroyed retinal structures, would be refractory to anti-VEGF. Moreover, sometimes the response to anti-VEGF agents changed. Additionally, it is thought that repeated fluid accumulation behind the eye could change the efficacy of follow-up injections. Moreover, the possibility that previous photodynamic therapy [PDT], gas injection, vitrectomy, or frequent injections in the early stages could avoid such prolonged disease states was a likely assumption of clinicians. Finally, it was a challenge to determine possible responses to anti-VEGF treatment in undertreated AMD cases because few related studies existed.

Some reports have suggested stopping treatment for very advanced cases of ARMD $[5,6]$. However, we sometimes encounter massive intraretinal fluid (IRF) after long periods of no treatment. In such cases, antiVEGF injection could not sufficiently dry the macula. Refractoriness was caused by the greatest linear dimension [7], excessive inflammatory cytokine levels [8], condition of the retinal pigment epithelium, and so on. 
However, in such cases, the damaged retinal structures caused by long-persistent IRF may be responsible for anti-VEGF resistance, so efforts should be made to avoid such conditions.

Algvere et al. reported that in 13 subjects, VA with ARMD lasting 13-30 months was improved over 6 months [9]. Gianniou et al. reported that among 76 subjects with persistent fluid after 12-month visits with monthly injections, VA improved during the subsequent 36 months [10]. Takahashi et al. reported that the mean total injection delay per year in a rural hospital was 147 days, although VA improved [11]. These reports suggest a relationship between the duration of IRF or SRF and VA, although the duration of fluid persistence was never calculated. There has been no previous report on whether the amount of accumulated fluid, with the accompanying destruction of retinal structure, is due to anti-VEGF injection refractoriness.

In this study, we retrospectively examined patients with poor VA and with long-term follow-up at our hospital, who underwent pro re nata treatment or even less frequent treatment to elucidate the best treatment options for these subjects. We investigated the relationships between injection-refractoriness and long-standing continuous IRF and repeated accumulation of IRF or SRF. Moreover, we investigated the changing patterns of effects of anti-VEGF injections and differences in the treatment courses between each pattern. We also investigated the effects of previous PDT, gas injection, vitrectomy on later courses as well as the relationships between continuous IRF and repeated accumulation of IRF or SRF and VA change.

\section{Methods}

The Ethics Committee of Toho University Sakura Medical Center approved this study (No. S18030). The procedures used conformed to the tenets of the Declaration of Helsinki. The study design was explained on the Sakura Medical Center website in accordance with the guidelines for clinical research set out by the Japanese Ministry of Health, Labor, and Welfare. All patients provided written informed consent for treatments; all private patient information was excluded from the database. The use of anonymous information was approved by the IRB without the need to seek further consent.

We examined consecutive patients with ARMD whose most recent visit to our hospital was from February 2018 to February 2019. Patients with VA $\leq 20 / 100$ or persistent subretinal hyper-reflective material (SHRM) and who visited our hospital for more than 10 months were included. Majority of previous studies defined the baseline VA as better than $20 / 100[1,5,7,12]$, and a few reports suggested that there were benefits in treating eyes with VA of $\leq 20 / 200$ [2,13]. We, therefore, examined subjects who visited our hospital between April 2006 and February 2019 , with a VA $\leq 20 / 100$ to determine the relationship between IRF/SRF and VA. We recorded type of CNV, presence or absence of persistent SHRM, total number of injections, span of injections (months/injection), number of PDT sessions, whether vitrectomy and gas injection were performed against SRH, baseline VA, and VA at the last visit. Persistent SHRM [14] was defined as that still present at the last visit. The number of injections was the total number of both aflibercept and ranibizumab injections.

Those who missed follow-up visits during observation periods and underwent direct laser photocoagulation for CNV were excluded from the study.

Before each analysis, we examined the effect of each injection throughout the observation period for all eyes and determined the summed duration of IRF or SRF for the appearance-disappearance period up to each 
injection as the accumulated IRF or SRF up to that injection. Each duration was calculated based on optical coherence tomography (OCT). We used the RTVue-100 (Optovue, Inc., Fremont, CA) and the Heidelberg Spectralis HRA $\triangle \mathrm{OCT}$ (Heidelberg Engineering $\mathrm{GmbH}$, Heidelberg, Germany). The effects were classified into three degrees: the disappearance of fluid was defined as completely effective (C), a decrease in fluid was considered partially effective $(P)$, and no change was defined as not effective $(N)$. Disappearance of fluid over a period of 3 months was not regarded as the effect of the injection, considering the half-life [15] and time needed for structural changes caused by anti-VEGF injection [16].

For the first analysis, we divided all subjects into two groups based on whether the longest persistent IRF was $\geq$ 10 months or $<10$ months. In various studies, subjects with an exudate present over 6-12 months were considered as having long-standing fluid, which could influence visual outcome [8,9,10];we distinguished such cases as having continuous IRF for $\geq 10$ months. We compared the total observation periods, injection span (months/injection) until the longest IRF, persistent SHRM, previous PDT, vitrectomy, and gas injection between the two groups. Therefore, the group with persistent IRF lasting $\geq 10$ months was further divided into two groups based on whether responses to injections were maintained or diminished during the longest persistent IRF period. If a $\mathrm{C}$ response diminished to a $\mathrm{P}$ or an $\mathrm{N}$ response, or if a $\mathrm{P}$ response diminished into an $\mathrm{N}$ response, the eye was classified into the diminished group. If the $P$ response was maintained, the eye was classified into the maintained group. Moreover, the two groups were compared in terms of injection numbers during the IRF period, injection span, whether PDT was performed at the period before or during the longest IRF period, duration of previous accumulated IRF, previous accumulated SRF, and proportion of CNV type.

In our second analysis, we examined if the effect of the injection had changed during the whole observation period; for cases in which change was observed, the patterns were classified.

Next, we examined the relationships between changes in LogMAR of BCVA and total accumulated IRF, SRF, and the longest persistent IRF period over 36 months from the time that the BCVA of each eye first declined to $\leq 20 / 100$. Eyes with shorter observation periods and eyes that had undergone cataract surgery during the 36month period were not included in the analysis.

\section{Statistical Analysis}

We applied the Mann-Whitney U test, Wilcoxon's signed-rank test, Fisher's exact test, and the Kruskal-Wallis test using Statcel 3 software 2011 (OMS Publishing Inc., Saitama, Japan). P < 0.05 was considered to indicate significant differences.

\section{Results}

Table 1 shows the characteristics of the enrolled eyes. A total of eighty-nine eyes of 80 patients were analysed. Table 2 shows the differences in the clinical features between eyes that had the longest continuous period $\geq 10$ months and those with a shorter period. Persistent SHRM tended to be present more often in the $\geq 10$-months IRF group, although this trend was not significant $(p=0.118)$. Table 3 shows the differences between the maintained group and diminished group among the longest IRF $\geq 10$ months. Twelve eyes were included in the maintained group and eleven eyes in the diminished group. Four eyes that were injection naïve and five eyes that had received a single injection were not included in the analyses. Injection span was much shorter in the 
diminished group than in the maintained group $(\mathrm{p}=0.043)$. PDT during the longest IRF period was performed in $2 / 11(18.2 \%)$ eyes in the diminished group and never in the maintained group $(p=0.048)$. Moreover, there were no significant differences in terms of previous performance of gas injection and vitrectomy between the two groups (data not shown). Polypoidal choroidal vasculopathy (PCV) or occult ARMD was present in 11/20 (55\%) in the maintained group and 10/11 (91\%) in the diminished group ( $p=0.044)$. Table 4 shows the changing patterns. A C response throughout the study period was in 16 eyes. Efficacy changed from $C$ to $P$, and thereafter did not change, in four eyes. In eight eyes, the following was observed: $C \rightarrow P \rightarrow C$. In 19 eyes, the following was observed: $\mathrm{P} \rightarrow \mathrm{C}$. In four eyes, the following was observed: $\mathrm{P} \rightarrow \mathrm{C}$. In 12 eyes, a $\mathrm{P}$ response was observed throughout the study. Other more complex patterns were seen in 16 eyes, and 10 eyes received $\leq$ three injections. Table 5 shows the timing of each pattern change from the first visit, the timing from the appearance of persistent SHRM, the total accumulated IRF up to the change, total accumulated SRF up to the change, number of injections, and injection span. Moreover, aflibercept/ranibizumab use, switching drugs, and previous treatment. The changes in the proportion of $\mathrm{C}, \mathrm{P}$, and $\mathrm{N}$ responses according to the total accumulated IRF and SRF up to 70 months seemed to have no clear tendency for diminishing or increasing anti-VEGF response (Data not shown). Table 6 shows the correlations between logMAR BCVA changes at 36 months from the point where the BCVA of each eye declined to $\leq 20 / 100$. BCVA change had no significant correlation with accumulated IRF or SRF but was somewhat correlated with the longest persistent IRF $\left(r_{S}=0.0867,0.0960\right.$, and $0.3158 ; P=0.528$, 0.485 , and 0.022 , respectively).

\section{Discussion}

The EVEREST study [17] reported that ranibizumab and PDT combination therapy was superior to monotherapy, and previous gas injection [18] or vitrectomy [19] were reported to decrease the activity of ARMD. In our study, previous PDT, gas injection, and vitrectomy had no effect on either shortening the persistent IRF period or maintaining the effect of anti-VEGF injections. The effect of PDT, gas injection, and vitrectomy could perhaps be altered in long standing undertreated AMD.

Contrary to our hypothesis, we found that long-standing oedema and refractoriness to anti-VEGF injection were rarely related. Among eyes with longest IRF $\geq 10$ months, the efficacy was retained for 20/31 eyes. Moreover, we found that injection span was shorter and proportion of occult CNV and PCV were much higher in the diminished group than those in the maintained group. Suzuki et al. reported that eyes with multiple polyps exhibited a higher prevalence of residual fluid after ranibizumab injection and a shorter mean interval between injections [7]. It is possible that similar subjects were included in the diminished group in our study. The diminished responses to the injection may have been caused mainly by CNV rather than by undertreatment.

Moreover, during the longest persistent IRF period and the whole observation period, the previously accumulated IRF and SRF seemed to be poorly associated with the diminished effect. Thus, injection refractoriness is not caused by repeated invasion of fluid.

In terms of effect change patterns, the timing of a $C \rightarrow P$ change occurred much later than a $P \rightarrow C$ change. It is possible that a $\mathrm{C} \rightarrow \mathrm{P}$ change was caused after repeated injections in individuals with excessive inflammatory cytokines [8], while a $\mathrm{P} \rightarrow \mathrm{C}$ change was caused by tachyphylaxis when the neutralizing antibody was produced [20]. Additionally, the injection span up to the $P \rightarrow C$ in a $C \rightarrow P \rightarrow C$ pattern was shorter than that up to a $C \rightarrow P$ in a $\mathrm{P} \rightarrow \mathrm{C} \rightarrow \mathrm{P}$ pattern. It is possible that in these later changes the initial cytokines or neutralizing antibody did not 
change significantly and the injection span directly influenced the effect. The $P \rightarrow C$ change in a $P \rightarrow C \rightarrow P$ pattern commonly occurred in conjunction with a high aflibercept/ranibizumab ratio than with a $\mathrm{C} \rightarrow \mathrm{P}$ change in a $\mathrm{C} \rightarrow \mathrm{P} \rightarrow \mathrm{C}$ pattern. These different effects according to pharmacological differences also occurred in the earlier periods.

In this study, there was little relationship between VA changes during the 36 months period in those subjects with a baseline VA $\leq 20 / 100$ and the total accumulated IRF or SRF. Nevertheless, a relationship between exudative persistence and worse VA has been frequently reported [1-5]. In our study, the primary reason for the weak association between repeated exudates and VA decline is that comparisons were performed among undertreated individuals with worse VA than reported in previous studies $[1,5,7,12]$. It could be conjectured that changes in retinal structure would be slowly exacerbated by repeated accumulation of IRF and SRF; however, the rough basal structures and functions would be retained to some extent. There was also a significant correlation between LogMAR change and the longest persistent IRF duration. This emphasizes the need to avoid long persistent IRF. Continuous IRF could damage such basal structures and lead to further destruction and an irreversible condition.

This study highlighted some points about managing subjects who already have poor VA and who have been previously undertreated. First, the use of anti-VEGF injections should not be dismissed based on the levels of accumulated IRF or SRF. Second, refractoriness could be caused by various factors, and the exact mechanism remains unknown. The effect of injection could change during follow-up, including both diminishing and improving patterns, although there did not appear to be any unalterable patterns based on previous courses that followed injection. Third, in patients with long-standing persistent IRF, refractoriness may be caused by high primary CNV activity, particularly in cases with occult CNV or PCV. PDT is generally an effective method,

although a satisfactory response is unlikely without diligent injections in refractory cases. Fourth, efforts should be made to shorten the duration of continuous IRF persistence.

Our study had some limitations. First, the variety of observation periods could have influenced the results. Second, this was a retrospective study, and the IRF or SRF periods were influenced by each patient's visit interval. Further prospective studies would be needed to accurately reveal the relationship between fluids, injection refractoriness, and VA decline.

Diminished response to anti-VEGF treatment during periods of persistent IRF is rarely associated with undertreatment but more likely associated with high CNV activity. Refractoriness was not acquired due to increased accumulated IRF and SRF and the mechanism of acquired refractoriness to anti-VEGF remains unknown. The use of anti-VEGF injection should not be dismissed in cases with previous IRF or SRF accumulation, although its use should be strictly regulated in refractory patients with high CNV activity.

\section{Conclusion}

In conclusion, diminished response to anti-VEGF treatment during persistent IRF periods are rarely associated with undertreatment, and may rather be associated with high CNV activity. Refractoriness was also not acquired due to increased accumulated IRF and SRF. The mechanism of acquired refractoriness to anti-VEGF remains unknown; moreover, the changes in effect demonstrated various patterns. The timing of effect changes and previous injection spans differed slightly between different changing patterns. Moreover, the duration of 
persistent IRF was associated with VA decline. Our study findings indicate that the use of anti-VEGF injection should not be dismissed in cases with previous accumulation of IRF or SRF, although it should be strictly regulated in refractory patients with high CNV activity. Additionally, it is necessary to endeavor to shorten the duration of persistent IRF. Furthermore, it should be kept in mind that both refractoriness and improved efficacy of the injection may be acquired.

\section{Abbreviations}

IRF: intraretinal fluid

SRF: subretinal fluid

ARMD: age-related macular degeneration

CNV: choroidal neovasculopathy

$B C V A$ : best-corrected visual acuity

VEGF: anti-vascular endothelial growth factor

PDT: photodynamic therapy

OCT: optical coherence tomography

\section{Declarations}

Research involving Human Participants: The Ethics Committee of Toho University Sakura Medical Center approved this study (No. S18030). The procedures used conformed to the tenets of the Declaration of Helsinki. The study design was explained on the Sakura Medical Center website in accordance with the guidelines for clinical research set out by the Japanese Ministry of Health, Labor, and Welfare.

Ethical approval and consent to participate: Informed consent for treatments was written. This study was the retrospective study with no intervention. All private patient information was excluded from the database. The use of anonymous information was approved by the IRB without the need to seek further consent.

Consent for publication: Not Applicable.

Availability of data and material: The datasets generated and analysed during the current study are not publicly available because we are not able to permit any possibility to identify personal from treatment history nevertheless data is anonymity, but are available from the corresponding author on reasonable request.

Funding: No funding was obtained for this study.

Author's contributions: IY, MS, and TM conceived and designed the study. Acquisition and analysis of data was performed by IY and AS. IY and AS drafted the manuscript. MS and TM revised the manuscript critically. All authors read and approved the final manuscript. 
Disclosure of Potential Conflicts of interest: The authors have no financial/conflicting interests to disclose. There was no sponsorship or other support for this study. We received no statistical consultation or assistance.

\section{Acknowledgements}

We would like to thank Editage (www.editage.jp)for English language editing. The authors report no conflicts of interest.

\section{References}

1. Adrean SD, Chaili S, Ramkumar H, Pirouz A, Grant S (2018) Consistent long-term therapy of neovascular agerelated macular degeneration managed by 50 or more anti-VEGF injections using a treat-extend-stop protocol. Ophthalmology 125:1047-1053

2. Barthelmes D, Nguyen V, Daien V, Campain A, Walton R, Guymer R, Morlet N, Hunyor AP, Essex RW, Arnold JJ, Gillies MC; Fight Retinal Blindness Study Group (2017) Two year outcome of "treat and extend" intravitreal therapy using aflibercept preferentially for neovascular age-related macular degeneration. Retina 38:20-28

3. Hatz K, Prunte C (2016) Changing from a pro re nata treatment regimen to a treat and extend regimen with ranibizumab in neovascular age-related macular degeneration. $\mathrm{Br} \mathrm{J}$ Ophthalmol 100:1341-1345

4. Kvannli L, Krohn J (2017) Switching from pro re nata to treat-and-extent regimen improves visual acuity in patients with neovascular age-related macular degeneration. Acta Ophthalmol 95:678-682

5. Rofagha S, Bhisitkul RB, Boyer DS, Sadda SR, Zhang K; SEVEN-UP Study Group (2013) Seven-year outcomes in ranibizumab-treated patients in ANCHOR, MARINA, and HORIZON: a multicenter cohort study (SEVEN-UP). Ophthalmology 120:2292-2299

6. NICE Technology appraisal (2008) Pegaptanib and ranibizumab for the treatment of age-related macular degeneration. National Institute for Health and Care Excellence Technology Guidelines.

https://www.nice.org.uk/guidance/ta155. Accessed 1 August 2019

7. Suzuki M, Nagai N, Shinoda H, Uchida A, Kurihara T, Tomita Y, Kamoshita M, lyama C, Tsubota K, Ozawa Y (2016) Distinct responsiveness to intravitreal ranibizumab therapy in polypoidal choroidal vasculopathy with single or multiple polyps. Am J Ophthalmol 166:52-59

8. Pongsachareonnont P, Mak MYK, Hurst CP, Lam WC (2018) Neovascular age-related macular degeneration: intraocular inflammatory cytokines in poor responder to ranibizumab treatment. Clin Ophthalmol 12:1877-1885

9. Algvere PV, Steen B, Seregard S, Kvanta A (2008) A prospective study on intravitreal bevacizumab (Avastin) for neovascular age-related macular degeneration of different durations. Acta Ophthalmol 86:482-489

10. Gianniou C, Dinari A, Jang L, Mantel I (2015) Refractory intraretinal or subretinal fluid in neovascular agerelated macular degeneration treated with intravitreal ranibizumab. Retina 35:1195-1201

11. Takahashi H, Ohkubo Y, Sato A, Takezawa M, Fujino Y, Yanagi Y, Kawashima H (2015) Relationship between visual prognosis and delay of intravitreal injection of ranibizumab when treating age-related macular 
12. Shin JY, Woo SJ, Ahn J, Park KH (2013) Anti-VEGF-refractory exudative age-related macular degeneration: differential response according to features on optical coherence tomography. Korean J Ophthalmol 27:425-732

13. Toth L, Stevenson M, Chakravarthy U (2015) Anti-vascular endothelial growth factor therapy for neovascular age-related macular degeneration. Outcomes in eyes with poor initial vision. Retina 35:1957-1953

14. Kawashima Y, Hata M, Oishi A, Ooto S, Yamashiro K, Tamura H, Miyata M, Uji A, Ueda-Arakawa N, Tsujikawa A (2017) Association of vascular versus avascular subretinal hyperreflective material with aflibercept response in age-related macular degeneration. Am J Ophthalmol 181:61-70

15. Niwa K, Kakinoki M, Sawada T, Wang X, Ohji M (2015) Ranibizumab and Aflibercept: Intraocular pharmacokinetics and their effects on aqueous VEGF level in vitrectomized and nonvitrectomized macaque eyes. Invest Ophthalmol Vis Sci 56:6501-6505

16. Ahlers C, Golbaz I, Stock G, Fous A, Kolar S, Pruente C, Schmidt-Erfurth U (2008) Time course of morphologic effects on different retinal compartments after ranibizumab therapy in age-related macular degeneration. Ophthalmology 115:39-46

17. Koh A, Lee WK, Chen LJ, Chen SJ, Hashad Y, Kim H, Lai TY, Pilz S, Ruamviboonsuk P, Tokaji E, Weisberger A, Lim TH (2012) EVEREST study: efficacy and safety of verteporfin photodynamic therapy in combination with ranibizumab or alone versus ranibizumab monotherapy in patients with symptomatic macular polypoidal choroidal vasculopathy. Retina 32:1453-1464

18. Kimura M, Yasukawa T, Shibata T, Kato A, Hirano Y, Uemura A, Yoshida M, Ogura Y (2018) Flattening of retinal pigment epithelial detachments after pneumatic displacement of submacular hemorrhages secondary to age-related macular degeneration. Graefes Arch Clin Exp Ophthalmol 256:1823-1829

19. Ziada J, Hagenau F, Compera D, Wolf A, Scheler R, Schaumberger MM, Priglinger SG, Schumann RG (2018) Vitrectomy for intermediate age-related macular degeneration associated with tangential vitreomacular traction. A clinicopathologic correlation. Retina 38:531-540

20. Forooghian F, Cukras C, Meyerle CB, Chew EY, Wong WT (2009) Tachyphylaxis following intravitreal bevacizumab for exudative age-related macular degeneration. Retina 29:723-731

\section{Tables}

Table 1 Characteristics of subjects 


\begin{tabular}{lc}
\hline Characteristic & 89 \\
\hline Eyes, N & Male: 65 , Female: 15 \\
Sex & $80.89 \pm 12.67$ \\
Age & Classic 6 \\
Type & Occult CNV 20 \\
& PCV 43 \\
& RAP 4 \\
& Cannot be classified/no fluorescein angiography 16 \\
& $83 / 89$ (93\%) \\
Persistent SHRM (eyes) & No $85 /$ Yes 4 \\
Gas injection during observation (eyes) & No $82 /$ Yes 7 \\
Vitrectomy during observation (eyes) & Never $64 /$ Once $17 /$ Twice $6 /$ Three times 2 \\
Photo dynamic therapy (eyes) & $11.67 \pm 6.94$ (range: $0-33 \square$ \\
Total number of injections $\square$ & \\
(aflibercept or ranibizmab) & \\
(times) & $65.84 \pm 31.08$ \\
Total observation period (months) & $12.33 \pm 35.54$ \\
Injection span (months) $*$ & (range: 0 0 28 times) \\
Baseline logMAR VA & $0.566 \pm 0.463$ \\
Final logMAR VA & $1.047 \pm 0.378$ \\
\hline
\end{tabular}

*Two eyes never received injections

Data are given as mean \pm standard deviation or as a number.

VA, visual acuity; PCV, polypoidal choroidal neovasculopathy; RAP, retinal angiomatous proliferation; SHRM, subretinal hyper-reflective material, CNV, choroidal neovasculopathy

Table 2 Differences between eyes with the longest continuous IRF $<10$ months or $\geq 10$ months 


\begin{tabular}{|c|c|c|c|}
\hline & $\begin{array}{l}\text { Longest IRF duration < } \\
10 \text { months (43 eyes) }\end{array}$ & $\begin{array}{c}\text { Longest IRF duration } \geq \\
10 \text { months (40 eyes) }\end{array}$ & P value \\
\hline $\begin{array}{l}\text { Total observation period } \\
\text { (months) }\end{array}$ & $\begin{array}{c}65.84 \pm 28.47 \\
\text { (range: } 10-144 \text { ) }\end{array}$ & $\begin{array}{c}70.30 \pm 33.78 \\
\text { (range: } 17-148 \text { ) }\end{array}$ & $0.491^{\dagger}$ \\
\hline $\begin{array}{l}\text { Duration of longest } \\
\text { continuous IRF (months) }\end{array}$ & $\begin{array}{l}4.733 \pm 2.567 \\
\text { (range: } 1-9.5 \text { ) }\end{array}$ & $\begin{array}{c}38.09 \pm 30.28 \\
\text { (range: } 10-121 \text { ) }\end{array}$ & $\square 0.00001^{\dagger}$ \\
\hline $\begin{array}{l}\text { Previous mean injection } \\
\text { span until IRF (months) }\end{array}$ & $\begin{array}{c}5.329 \pm 3.466 \\
\text { (range: } 1.25-16.91 \text { ) }\end{array}$ & $\begin{array}{c}5.675 \pm 5.987 \\
\text { (range: } 1.2-7.33 \text { ) }\end{array}$ & $0.266^{\dagger}$ \\
\hline Persistent SHRM (eyes) & $38 / 43$ (88.3\%) & $39 / 40(97.5 \%)$ & $0.118^{*}$ \\
\hline $\begin{array}{l}\text { Previous gas injection } \\
\text { (eyes) }\end{array}$ & $3 / 43(6.98 \%)$ & $1 / 40(2.5 \%)$ & $0.336^{*}$ \\
\hline Previous vitrectomy (eyes) & $2 / 43(4.65 \%)$ & $4 / 40(10 \%)$ & $0.304^{*}$ \\
\hline Previous PDT (eyes) & $11 / 43(25.6 \%)$ & $8 / 40(20 \%)$ & $0.366^{*}$ \\
\hline
\end{tabular}

* Fisher's exact test (six eyes with no IRF were not included)

† Mann-Whitney U-test

IRF, intraretinal fluid; SHRM, Subretinal hyper-reflective material; PDT, photodynamic therapy

Table 3 Differences between diminished or maintained effect in eyes with continuous IRF $\geq 10$ months 


\begin{tabular}{|c|c|c|c|}
\hline & $\begin{array}{c}\text { Effect } \\
\text { maintained }\end{array}$ & $\begin{array}{c}\text { Effect } \\
\text { diminished }\end{array}$ & P-value \\
\hline Number (eyes) & $20 / 31(64.5 \%)$ & $11 / 31(35.4 \%)$ & \\
\hline Longest IRF period (months) & $26.98 \pm 20.42$ & $47.77 \pm 29.04$ & $0.010^{\dagger}$ \\
\hline $\begin{array}{l}\text { Number of injections during longest IRF } \\
\text { period }\end{array}$ & $\begin{array}{c}\text { (range: } 10-70 \text { ) } \\
3.70 \pm 1.34 \\
\text { (range: } 2-7 \text { ) }\end{array}$ & $\begin{array}{c}\text { (range: 18-95) } \\
10.73 \pm 6.51 \\
\text { (range: } 7-27 \text { ) }\end{array}$ & $\begin{array}{c}< \\
0.00001^{\dagger}\end{array}$ \\
\hline Injection span (months) & $7.59 \pm 6.98$ & $5.86 \pm 6.19$ & $0.043^{\dagger}$ \\
\hline PDT previous longest IRF period (eyes) & $\begin{array}{l}\text { (range: } 3.3-35) \\
5 / 20(25.0 \%)\end{array}$ & $\begin{array}{l}\text { (range: } 2.4-23) \\
2 / 11(18.2 \%)\end{array}$ & $0.664^{\square}$ \\
\hline PDT during longest IRF period (eyes) & $0 / 20(0 \%)$ & $2 / 11(18.2 \%)$ & $0.048^{\square}$ \\
\hline $\begin{array}{l}\text { Total accumulated IRF up to the longest IRF } \\
\text { period (months) }\end{array}$ & $\begin{array}{c}6.70 \pm 9.36 \\
\text { (range: } 0-37.5 \text { ) }\end{array}$ & $\begin{array}{c}3.80 \pm 8.08 \\
\text { (range: } 0-11.25)\end{array}$ & $0.223^{\dagger}$ \\
\hline $\begin{array}{l}\text { Total accumulated SRF up to the longest IRF } \\
\text { period (months) }\end{array}$ & $\begin{array}{c}9.06 \pm 9.29 \\
\text { (range: } 0-29.5 \text { ) }\end{array}$ & $\begin{array}{c}9.52 \pm 12.23 \\
\text { (range: } 0-32.75 \text { ) }\end{array}$ & $0.605^{\dagger}$ \\
\hline $\begin{array}{l}\text { Type of CNV } \\
\text { (Occult or PCV } \\
\text { /others) }\end{array}$ & $\begin{array}{c}\text { 11/20 (55\%) } \\
\text { (PCV 9/Occult } \\
\text { CNV 2) }\end{array}$ & $\begin{array}{c}\text { 10/11 (91\%) } \\
\text { (PCV 6/Occult } \\
\text { CNV 4) }\end{array}$ & $0.044^{\dagger}$ \\
\hline
\end{tabular}

Nine eyes with no injection or only one injection were not included.

Previous IRF was 0 if the longest IRF was the first IRF.

${ }^{\dagger}$ Mann-Whitney-U test

${ }^{\square}$ Fisher's exact test.

PDT, photodynamic therapy; IRF; intraretinal fluid; SRF, subretinal fluid; PCV, polypoidal choroidal vasculopathy; CNV, choroidal neovasculopathy

Table 4 Changing pattern of injection effects during total observation periods 


\begin{tabular}{ll}
\hline Completely effective & 16 \\
Completely effective $\rightarrow$ Partially effective & 4 \\
Completely effective $\rightarrow$ Partially effective $\rightarrow$ Completely effective & 8 \\
Partially effective $\rightarrow$ Completely effective & 19 \\
Partially effective $\rightarrow$ Completely effective $\rightarrow$ Partially effective & 4 \\
Partially effective & 12 \\
Other pattern & 16 \\
Too few injections (within three) & 10 \\
\hline
\end{tabular}

Table 5 Characteristics of the timing of each pattern change 


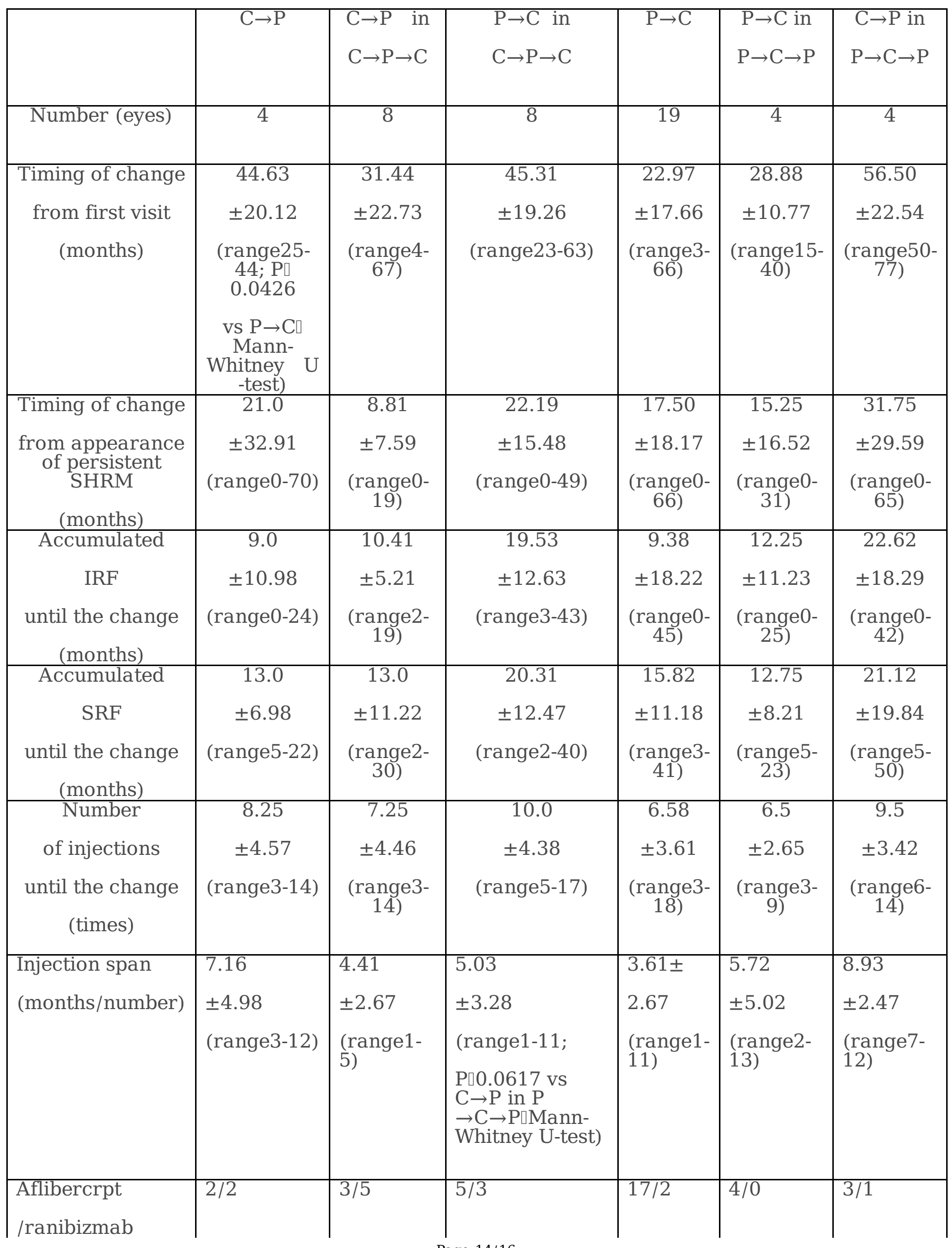




\begin{tabular}{|l|l|l|l|l|l|l|} 
& \multicolumn{1}{|l|}{$\begin{array}{l}\text { (P=0.038 } \\
\text { vs } \rightarrow \text { C in } \\
\text { P } \rightarrow \text { C } \rightarrow \text { P ; } \\
\text { Fisher's } \\
\text { exact } \\
\text { test) }\end{array}$} & 1 & 2 & & \\
\hline $\begin{array}{l}\text { Switching } \\
\text { Ranibizumab } \\
\rightarrow \text { Aflibercept, } \\
\text { Switching }\end{array}$ & 0 & 0 & 0 & 3 & 0 & 0 \\
$\begin{array}{l}\text { Aflibercept } \\
\rightarrow \text { Ranibizmab, } \\
\text { No switching } \\
\text { at the point }\end{array}$ & 3 & 7 & 6 & 1 & 0 & 1 \\
\hline Previous PDT & $1 / 4$ & $2 / 8$ & $0 / 8$ & 15 & 4 & 3 \\
\hline $\begin{array}{l}\text { Previous } \\
\text { Vitrectomy }\end{array}$ & $0 / 4$ & $1 / 8$ & $0 / 8$ & $3 / 19$ & $2 / 4$ & $0 / 4$ \\
\hline $\begin{array}{l}\text { Previous } \\
\text { gas injection }\end{array}$ & $0 / 4$ & $0 / 8$ & $0 / 8$ & $1 / 19$ & $1 / 4$ & $0 / 4$ \\
\hline
\end{tabular}

Vertical row shows each pattern of change and horizontal line shows the characteristics of the change timing.

Other pairs were not significantly different (Mann-Whitney U test, Wilcoxon signed-rank test, Kruskal-Wallis test)

$\mathrm{C}=$ completely effective; $\mathrm{P}=$ partially effective

Note: $\mathrm{C} \rightarrow \mathrm{P}$ in $\mathrm{C} \rightarrow \mathrm{P} \rightarrow \mathrm{C}$ (the whole change pattern is completely effective $\rightarrow$ partially effective $\rightarrow$ completely effective, and this row describes effect change completely effective $\rightarrow$ partially effective.

Table 6 Visual acuity change from baseline 20/100 during the 36 months interval, the total accumulated IRF and SRF periods, and longest continuous IRF period 


\begin{tabular}{lcccc}
\hline $\begin{array}{l}\text { VA change } \\
\text { (nø54) } \\
\text { (logMAR BCVA change) }\end{array}$ & Parameter & $\begin{array}{c}\text { Duration } \\
\text { (months) }\end{array}$ & Rs & P-value \\
\hline $\begin{array}{l}\text { 0.0879 } \pm 0.396 \\
\text { (range: 0.69-1.18) }\end{array}$ & Total added IRF & $17.10 \pm 12.85(0-36)$ & 0.0867 & 0.528 \\
& Total added SRF & $15.50 \pm 10.43$ & 0.0960 & 0.485 \\
& Longest continuous IRF & $24.35 \pm 28.94$ & 0.3158 & 0.022 \\
& & $(0-121.5)$ & & \\
\hline
\end{tabular}

Spearman's correlation coefficient by rank test

BCVA, best corrected visual acuity; IRF, intraretinal fluid; SRF, subretinal fluid 